\title{
The association between alcohol restriction policies and vehicle- related mortality in Cali, Colombia, 1998-2008
}

\author{
Jorge Mena ${ }^{1,2,3}$, Álvaro I Sánchez ${ }^{2,3}$, María Isabel Gutiérrez ${ }^{2}$, Juan-Carlos Puyana ${ }^{3}$, and Brian Suffoleto ${ }^{1}$ \\ ${ }^{1}$ Department of Emergency Medicine, University of Pittsburgh, U.S.A. \\ ${ }^{2}$ CISALVA Institute, Universidad del Valle, Cali, Colombia \\ ${ }^{3}$ Department of Surgery, University of Pittsburgh, U.S.A.
}

\begin{abstract}
Aims: To determine whether the implementation of alcohol control policies was associated with changes in the incidence of road traffic deaths.

Design: Ecologic study conducted using an interrupted time series analysis. Full restrictive polices banned alcohol between 6 p.m. and 6 a.m. Most restrictive polices prohibited alcohol between 1 a.m. and 10 a.m. Restrictive policies prohibited alcohol between 2 a.m. and 10 a.m. Moderately restrictive policies banned alcohol between 3 a.m. and 10 a.m. Lax policies prohibited alcohol between 4 a.m. and 10 a.m.
\end{abstract}

Setting: We used data of road traffic mortality in the population of Cali, Colombia from 1998 to 2008.

Participants: The population of Cali in 2008 was 2,184,753 inhabitants; 47\% were male.

Measures: Aggregated daily counts of road traffic deaths. Restrictive policies were compared with lax policies to estimate the effect of reducing hours of alcohol availability using multiple negative binomial regressions.

Findings: There was a decreased risk of road traffic mortality in periods when moderately restrictive policies were in effect $(\mathrm{IRR}=0.84,95 \%$ CI $0.72-0.97, p=0.019)$. There was an even lower risk of road traffic deaths in periods when most restrictive policies were in effect (IRR $=0.70,95 \%$ CI $0.58-0.85, p<0.001$ ). In motorcyclists, most restrictive (IRR 0.55, 95\% CI 0.38$0.81, p=0.002$ ) and full restrictive policies (IRR 0.52, 95\% CI 0.29-0.94, $p=0.032$ ) were associated with decreased risk of mortality.

Conclusions: Our findings support more restrictive alcohol control policies to reduce road traffic mortality. Specifically, reducing the time of alcohol availability was associated with a decrease in road traffic death rates.

Worldwide, there are 268,246 alcohol-attributable deaths due to road accidents each year (World Health Organization, 2011), which may account for up to a third of all traffic-related deaths (Transportation, 2009). Effective measures to reduce alcohol-impaired driving and the associated morbidity and mortality include alcohol taxation, increasing the age limit for legal purchase of alcohol, reducing the number of places that sell alcohol on or off their premises, enforcing regulations for licenses to sell alcohol, and conducting breath tests on drivers (Babor et al., 2010). As well, restricting the hours or days of sale of alcohol directly reduces the prevalence of excessive alcohol consumption and impaired driving (Hahn et al., 2010; Middleton et al., 2010). Little is known about how alcohol control policies that limit the hours during which alcohol may be sold and publicly consumed affect actual traffic-related deaths.
Cali is the third largest city in Colombia. Between 1998 and 2008, there were 3,946 road traffic deaths in this citya rate of 17 per 100,000 inhabitants (CISALVA, 2008), higher than the rates of Colombia as a whole and the United States (World Health Organization, 2010) (see Figure 1). During this period, several policies were implemented that aimed to restrict alcohol availability after certain hours (Guerrero \& Concha-Eastman, 2001). Prior work from our group showed that lax policies were associated with a higher risk of homicides, compared with more restrictive policies (Sanchez et al., 2011). In this study, we examined the association between policies limiting hours when alcohol may be sold and/or publicly consumed and road traffic deaths in Cali.

Correspondence: Jorge Mena, MD, MS, Department of Emergency Medicine, University of Pittsburgh, 3600 Forbes Avenue, Iroquois Building, suite 400A, Pittsburgh, Pennsylvania, 15261. Telephone: (412) 864-3833; Fax Number: (412) 647-6999; E-mail: jorgehmena@gmail.com; jhm26@pitt.edu; menamunozjh@upmc.edu

Financial support: National Institutes of Health’s Fogarty International Center grant 1D43-TW007560

Keywords: Road traffic safety, traffic deaths, alcohol control policies, Cali-Colombia, time series 
Figure 1

Comparative of road traffic death rates between Cali, Colombia and other countries (per 100,000 population)

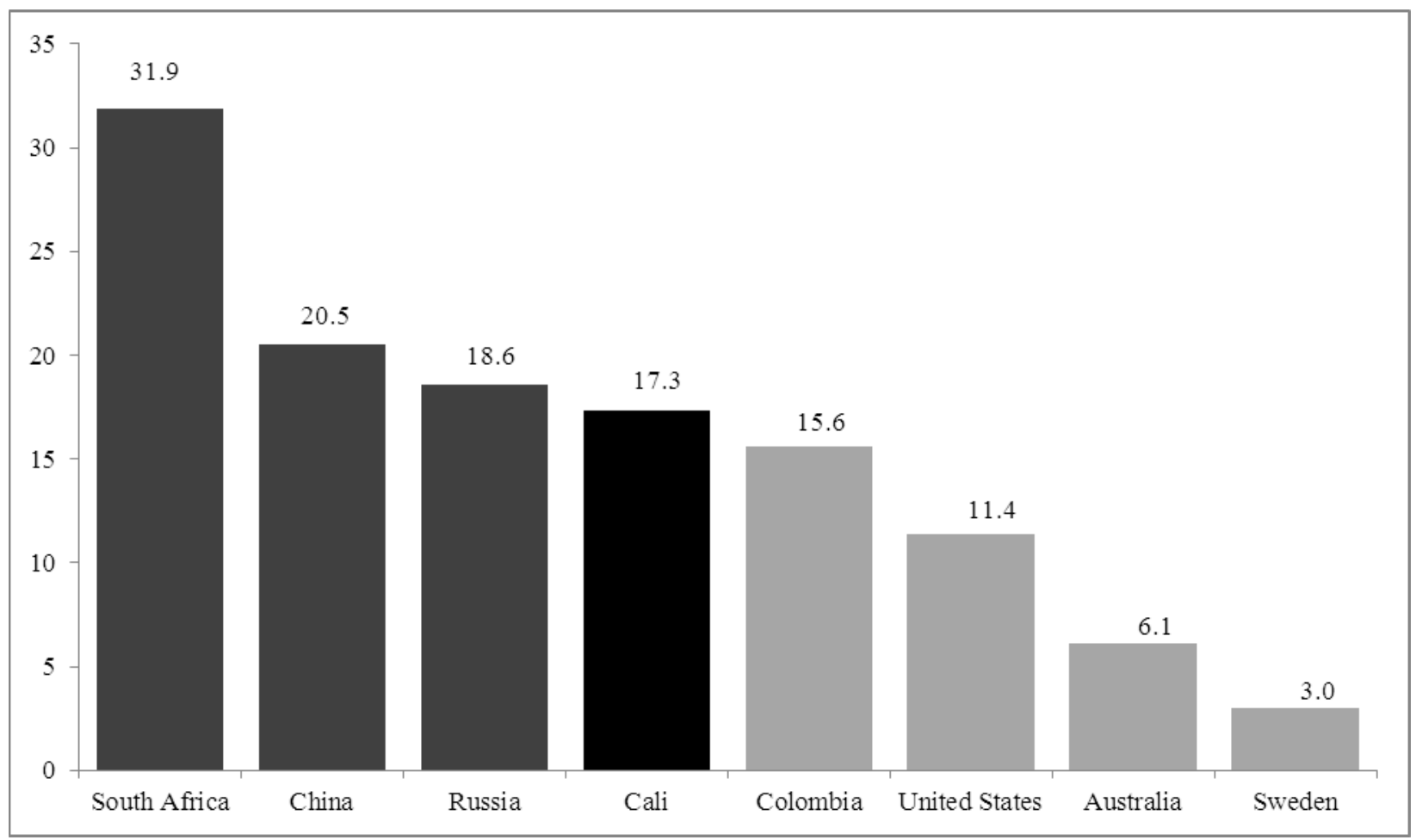

\section{Methods}

\section{Study Design and Settings}

This ecologic study used data on road traffic mortality and focused on the population of the city of Cali from January 1, 1998 to December 31, 2008. During these 4,018 days, policies limiting the sale and public consumption of alcohol were in effect continuously, but with variations in the hours of restriction. Because these variations were applied intermittently, we used an interrupted time series design with multiple replications to compare periods with different interventions (Cook, 1979; Kedem, 2002).

\section{Study Data}

The Cali Crime Observatory collects demographic and related information on all injury deaths. This data source is coordinated by the Mayor's Office and is produced by several different governmental entities. It has been recognized as an efficient and opportune injury surveillance system that makes data available at the local level (ConchaEastman, Espitia, Espinosa, \& Guerrero, 2002; GutierrezMartinez, 2007; Villaveces et al., 2000). We requested deidentified information, which includes sex and age, mode of transport, and the date and hour of the injury.

\section{Population}

The city of Cali is one of the fastest-growing economies in the country. Nightlife is an important part of the culture and economic activity of the city (Concha-Eastman, Espitia, Espinosa, \& Guerrero, 2002; Guerrero \& ConchaEastman, 2001). The structure of the population of Cali was obtained from the census of 2005 performed by the National Administrative Department of Statistics (DANE). According to the conciliation performed after the census, the population in 1998 was 1,950,878. Agreeing with the projections based in this census, the population in 2008 increased to 2,184,753 (DANE, 2010).

\section{Alcohol Restriction Policies}

Regulation occurred at the local level, coordinated through the Mayor's Office and disseminated to the public through mass media. The limitation of sale of alcohol is here defined as "applying regulatory authority to limit the hours that alcohol may be sold at on and off-premises alcoholic beverage outlets." On-premises retailing refers to the sale of alcohol for consumption at the point of sale (e.g., at bars, restaurants, or clubs); off-premises retailing refers to the sale of alcohol for consumption elsewhere (e.g., at liquor stores, grocery stores, or convenience stores).

Different types of policies made reference to the restriction of alcohol. The first policy was defined as full-restrictive 
and prohibited alcohol between 6 p.m. and 6 a.m. of the next day during 97 non-consecutive days; it was implemented during political elections and national security warnings. The second policy was defined as most restrictive and prohibited alcohol sales between 1 a.m. and 10 a.m. during 300 non-consecutive days. The third policy was defined as restrictive and established the prohibition of alcohol between 2 a.m. and 10 a.m. during 1,589 nonconsecutive days. The fourth type of policy was defined as moderately restrictive and banned alcohol between 3 a.m. and 10 a.m. during 1,759 non-consecutive days. Lax policies prohibited alcohol between 4 a.m. and 10 a.m. during 273 non-consecutive days occurring in August and the last week of December. Figure 2 indicates when each of the policies was in force between 1998 and 2008.

Data on how policies were disseminated was obtained from the Mayor's Office archives. Enforcement of the policies was carried out by local law enforcement through the use of random checkpoints throughout the city to identify individuals under the influence of alcohol. The standard procedure was to arrest individuals who were consuming or vending alcohol, close places where alcohol beverages were being consumed or sold at forbidden times, and take vehicles off the road if the driver was intoxicated.

\section{Outcome Measures}

The main outcome measure was the aggregated daily count of all traffic-related deaths. Secondary outcome measures were the separate aggregated daily counts of deaths of motorcyclists, drivers/passengers of vehicles, pedestrians, and cyclists. We computed mortality rates using the estimates of population by age, sex and year in order to calculate person-years of exposure (Villaveces et al., 2000).

\section{Statistical Analysis}

We fitted multiple negative binomial regression models to the daily crash fatality counts to test the effects of alcohol restrictions on overall traffic-related mortality and on the daily fatality counts of different road users. This method accounts for the non-normality and over-dispersion of data and allow us to adjust for different confounders (Eger, 2006; Kedem, 2002; Villaveces et al., 2000). Restrictive policies were compared with lax policies in order to estimate the effect of reducing hours of alcohol sales and consumption.

We based the selection of variables on two previous studies performed in the city. The first one evaluated the impact of public policies on the mortality rates of motorcyclists. The second one analyzed the effects of restriction of alcohol on the rates of homicides (Espitia-Hardeman et al., 2008; Sanchez et al., 2011).

\section{Figure 2}

Time-series plot of alcohol restriction policies and aggregated daily counts of traffic deaths in Cali, Colombia, 1998-2008

\section{Alcohol restriction policies}

Cali, Colombia. 1998-2008

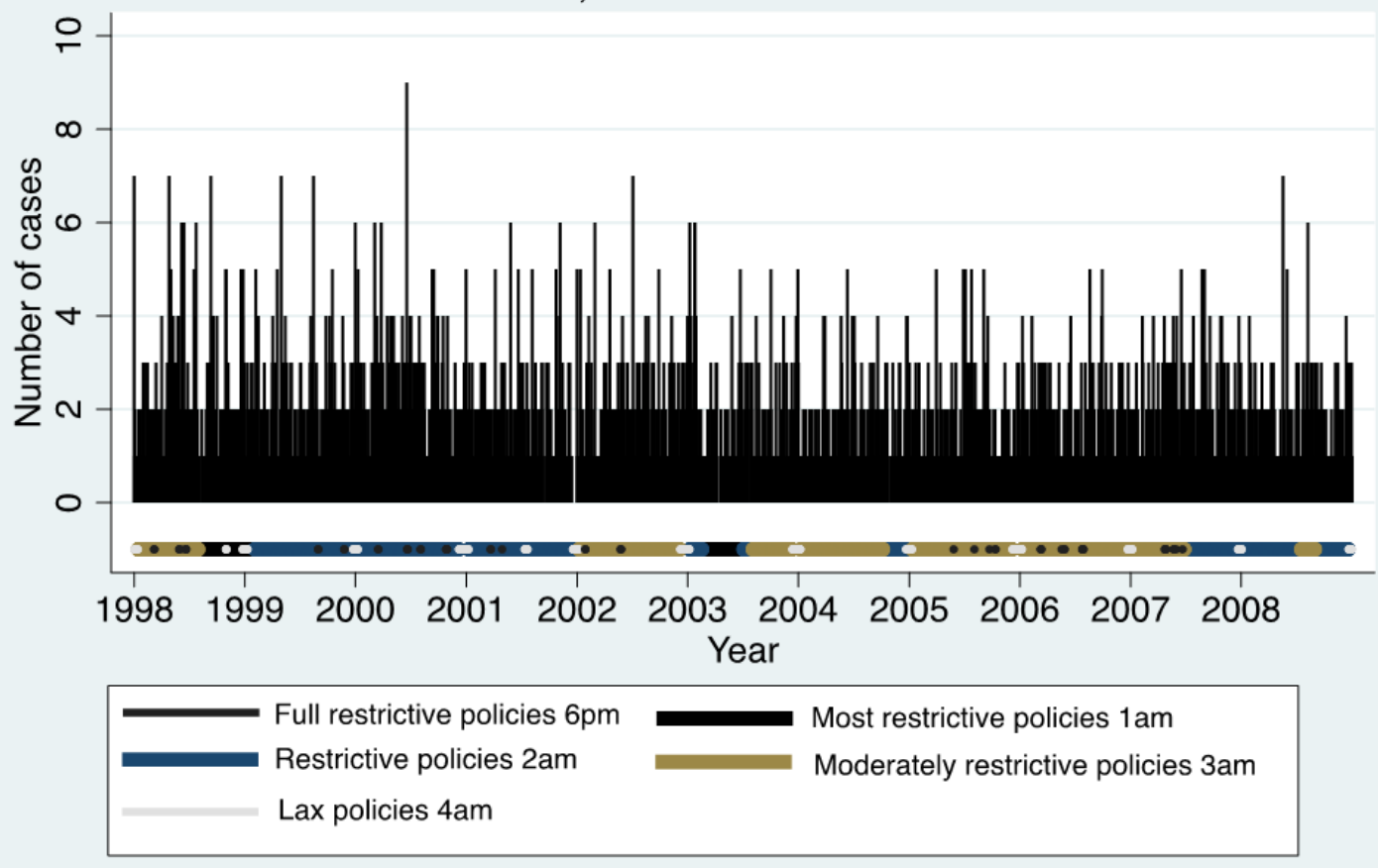


Since policy type was defined by the hours of restriction, we used the predictive mean-matching imputation method to avoid missing values in the hour of injury occurrence (Landerman, Land, \& Pieper, 1997). Because traffic injury deaths and alcohol consumption both increased on weekends, we categorized the days of the week as weekdays (Monday through Thursday) and weekends (Friday through Sunday). We also created a variable to account for the effects of holidays and generated an interaction term between weekends and holidays (Villaveces et al., 2000).

We explored the confounding effect of motorcycle-specific policies. These policies were applied intermittently. Since 1998, the use of helmets has been mandatory, and law enforcement institutions have prohibited passengers on motorcycles as a safety measure. In addition, the Mayor's Office banned motorcycle traffic after certain hours of the night. Since 2001, reflective jackets have been mandatory (Espitia-Hardeman et al., 2008).

In Cali, mayors were elected to serve three-year terms during the period from 1998 to 2003, and have served fouryear terms since 2004. The Cali mayor elected for 2004 2007 was removed before his term was completed, and there was a provisional administration for 14 days, followed by a new one delegated by the national government for less than a year. Finally, a new mayor was elected in 2008. We created a variable with the exact number of days of every administration, in order to take Cali's political context into account.

We explored the potential confounding effect of a national policy that has been in effect since November 8 of 2002 and December 31 of 2008 . The national code of traffic regulation was changed to include economic sanctions, and vehicles were detained if the driver was found to be under the influence of alcohol.

Finally, we estimated two fractional polynomials to account for annual overall trends (Royston \& Altman, 1994). We also accounted for seasonality by the estimation of sinecosine pairs with annual periodicity (Perez, MarlDell'Olmo, Tobias, \& Borrell, 2007). These estimations were performed for the main outcome and separately for every subgroup of road users. The final regression models accounted for age, sex, weekends, holidays, motorcyclespecific policies, political administrations, national policy, fractional polynomials and sine-cosine pairs.

Traffic injury death rates were higher during 2000. This increment can be explained by the decrease of traffic police personnel in the city, but also by factors not accounted for in our analysis. After this peak, there was a drop in mortality during 2001. Sensitivity analyses were performed from 2001 to 2008 to evaluate the robustness of the estimations. The rationale for this analysis was to demonstrate that this drop of mortality had no statistical influence on the effects of alcohol restriction policies. All the regression models were fitted using STATA (Version 11). Results are presented as incidence rate ratios (IRR) with 95\% CI and P-values (Vittinghoff E., 2005).

\section{Results}

\section{Descriptive Analysis}

There were 3,946 traffic-related deaths, with a rate of 17.31 per 100,000 person years. Pedestrians accounted for 45.5\%; motorcyclists were $27.3 \%$; cyclists $12.9 \%$; and vehicle occupants $12.6 \%$. The year 2000 had the highest incidence of traffic-related deaths. Mortality was higher on weekends and holidays. Males had higher mortality. Incidence of traffic injury deaths was lower after the modification of the national traffic code in 2002. The highest incidence of traffic injury occurred under the first political administration during the study period. Table 1 summarizes the number of cases and the incidence rates by sex, age and other covariates.

Regarding the preventive policies for motorcyclists, prohibition of motorcycle traffic after 11 p.m. was associated with the lowest rates of mortality. The helmet law and the prohibition of passengers were both also associated with lower incidence rates. Table 2 depicts the cases and the incidence rates for different type of preventive policies for motorcycles.

We observed the highest incidence rate of traffic road deaths when the least restrictive policy was in effect. The lowest incidence rate in overall mortality was observed during the most restrictive policies. The lowest rates for motorcyclists were observed during the most restrictive and full restrictive policies. Table 3 summarizes the number of cases and incidence rates according to the different alcohol restriction policies.

\section{Multivariate Analysis}

The moderately restrictive policy (IRR 0.84 , 95\% CI $0.72-$ $0.97, p=0.019$ ) and the most restrictive policy (IRR 0.70, 95\% CI 0.58-0.85, $p<0.001$ ) were associated with decreased risk of road traffic deaths. In motorcyclists, most restrictive (IRR $0.55,95 \%$ CI $0.38-0.81, p=0.002$ ) and full restrictive policies (IRR 0.52, 95\% CI 0.29-0.94, $p=$ 0.032 ) were associated with decreased risk of death. In pedestrians, most restrictive policy was associated with decreased risk of mortality (IRR $0.71,95 \%$ CI 0.54-0.93, $p$ $=0.012$ ). Table 4 summarizes the unadjusted analysis and multivariate analysis results.

\section{Sensitivity Analyses}

Multivariate comparisons after 2000 demonstrated that moderately restrictive (IRR 0.83 , 95\% CI $0.70-0.99, p=$ 0.003 ) and most restrictive policies (IRR 0.73 , 95\% CI $0.55-0.97, p=0.028$ ) were associated with decreased risk of road traffic deaths. For motorcyclists, moderately restrictive (IRR 0.66, 95\% CI 0.48-0.91, $p=0.012$ ), most restrictive (IRR $0.46,95 \%$ CI $0.26-0.83, p=0.009$ ) and full restrictive policies (IRR 0.38, 95\% CI 0.16-0.90, $p<$ 0.001 ) were associated with a decreased risk of mortality. Table 5 summarizes the results of the sensitivity analysis. 
Table 1.

Numbers of cases and incidence rates per 100,000 person-years of traffic deaths. Cali, Colombia, 1998-2008

\begin{tabular}{|c|c|c|c|c|c|c|c|c|c|c|}
\hline & \multicolumn{10}{|c|}{ Traffic Injury Deaths } \\
\hline & \multicolumn{2}{|c|}{ Overall Mortality } & \multicolumn{2}{|c|}{ Motorcyclists } & \multicolumn{2}{|c|}{ Vehicle } & \multicolumn{2}{|c|}{ Pedestrians } & \multicolumn{2}{|c|}{ Cyclists } \\
\hline & Cases & Rate & Cases & Rate & Cases & Rate & Cases & Rate & Cases & Rate \\
\hline \multicolumn{11}{|l|}{ Study Period } \\
\hline $1998-2008$ & 3,946 & 17.31 & 1,076 & 4.72 & 499 & 2.19 & 1,794 & 7.87 & 508 & 2.23 \\
\hline \multicolumn{11}{|l|}{ Years } \\
\hline 1998 & 411 & 21.07 & 110 & 5.64 & 53 & 2.72 & 198 & 10.15 & 46 & 2.36 \\
\hline 1999 & 398 & 20.15 & 107 & 5.42 & 72 & 3.65 & 177 & 8.96 & 35 & 1.77 \\
\hline 2000 & 467 & 23.36 & 145 & 7.25 & 70 & 3.50 & 197 & 9.86 & 54 & 2.70 \\
\hline 2001 & 333 & 16.39 & 67 & 3.30 & 47 & 2.31 & 176 & 8.66 & 42 & 2.07 \\
\hline 2002 & 358 & 17.50 & 96 & 4.69 & 47 & 2.30 & 165 & 8.07 & 49 & 2.40 \\
\hline 2003 & 346 & 16.72 & 79 & 3.82 & 52 & 2.51 & 159 & 7.68 & 53 & 2.56 \\
\hline 2004 & 315 & 15.04 & 71 & 3.39 & 37 & 1.77 & 143 & 6.83 & 55 & 2.63 \\
\hline 2005 & 308 & 14.53 & 67 & 3.16 & 31 & 1.46 & 152 & 7.17 & 53 & 2.50 \\
\hline 2006 & 326 & 15.20 & 100 & 4.66 & 35 & 1.63 & 135 & 6.29 & 39 & 1.82 \\
\hline 2007 & 358 & 16.50 & 110 & 5.07 & 24 & 1.11 & 153 & 7.05 & 55 & 2.53 \\
\hline 2008 & 326 & 14.85 & 124 & 5.65 & 31 & 1.41 & 139 & 6.33 & 27 & 1.23 \\
\hline \multicolumn{11}{|l|}{ Days of the week } \\
\hline Weekdays & 1886 & 14.48 & 476 & 3.65 & 208 & 1.60 & 916 & 7.03 & 245 & 1.88 \\
\hline Weekends & 2060 & 21.09 & 600 & 6.14 & 291 & 2.98 & 878 & 8.99 & 263 & 2.69 \\
\hline \multicolumn{11}{|l|}{ Holidays } \\
\hline Non-Holidays & 3683 & 17.09 & 987 & 4.58 & 459 & 2.13 & 1685 & 7.82 & 492 & 2.28 \\
\hline Official Holidays & 263 & 21.16 & 89 & 7.16 & 40 & 3.22 & 109 & 8.77 & 16 & 1.29 \\
\hline \multicolumn{11}{|l|}{ Age (in years) } \\
\hline$<5$ & 66 & 3.34 & 4 & 0.20 & 11 & 0.56 & 50 & 2.53 & 1 & 0.05 \\
\hline $5-9$ & 61 & 2.89 & 5 & 0.24 & 4 & 0.19 & 47 & 2.23 & 5 & 0.24 \\
\hline $10-14$ & 75 & 3.52 & 10 & 0.47 & 15 & 0.70 & 28 & 1.31 & 21 & 0.98 \\
\hline $15-19$ & 270 & 12.72 & 110 & 5.18 & 44 & 2.07 & 55 & 2.59 & 54 & 2.54 \\
\hline $20-24$ & 394 & 19.02 & 237 & 11.44 & 51 & 2.46 & 60 & 2.90 & 41 & 1.98 \\
\hline $25-29$ & 420 & 21.81 & 220 & 11.42 & 62 & 3.22 & 91 & 4.73 & 40 & 2.08 \\
\hline $30-34$ & 324 & 17.82 & 159 & 8.74 & 44 & 2.42 & 82 & 4.51 & 35 & 1.92 \\
\hline $35-39$ & 291 & 16.59 & 112 & 6.38 & 61 & 3.48 & 79 & 4.50 & 35 & 2.00 \\
\hline $40-44$ & 276 & 17.40 & 85 & 5.36 & 41 & 2.58 & 98 & 6.18 & 49 & 3.09 \\
\hline 45-49 & 261 & 19.78 & 51 & 3.87 & 44 & 3.33 & 111 & 8.41 & 51 & 3.87 \\
\hline $50-54$ & 221 & 21.33 & 26 & 2.51 & 22 & 2.12 & 127 & 12.26 & 43 & 4.15 \\
\hline 55-59 & 204 & 25.39 & 25 & 3.11 & 19 & 2.37 & 111 & 13.82 & 44 & 5.48 \\
\hline $60-64$ & 232 & 36.04 & 10 & 1.55 & 19 & 2.95 & 163 & 25.32 & 35 & 5.44 \\
\hline 65-69 & 212 & 40.68 & 3 & 0.58 & 18 & 3.45 & 165 & 31.66 & 23 & 4.41 \\
\hline $70-74$ & 209 & 52.48 & 2 & 0.50 & 18 & 4.52 & 171 & 42.94 & 16 & 4.02 \\
\hline 75-79 & 174 & 59.16 & 3 & 1.02 & 11 & 3.74 & 148 & 50.32 & 8 & 2.72 \\
\hline$\geq 80$ & 205 & 72.98 & 2 & 0.71 & 9 & 3.20 & 189 & 67.28 & 1 & 0.36 \\
\hline \multicolumn{11}{|l|}{ Sex } \\
\hline Female & 794 & 6.69 & 169 & 1.42 & 142 & 1.20 & 455 & 3.83 & 19 & 0.16 \\
\hline Male & 3,098 & 28.36 & 895 & 8.19 & 351 & 3.21 & 1,318 & 12.07 & 482 & 4.412 \\
\hline \multicolumn{11}{|l|}{ National Traffic Code } \\
\hline No modification & 1,918 & 19.77 & 513 & 5.29 & 278 & 2.87 & 895 & 9.23 & 218 & 2.25 \\
\hline Modification & 2,028 & 15.49 & 563 & 4.30 & 221 & 1.69 & 899 & 6.86 & 290 & 2.21 \\
\hline \multicolumn{11}{|l|}{ Mayor's period } \\
\hline $1998-2000$ & 1,276 & 21.54 & 362 & 6.11 & 195 & 3.29 & 572 & 9.65 & 135 & 2.28 \\
\hline 2001-2003 & 1,037 & 16.87 & 242 & 3.94 & 146 & 2.38 & 500 & 8.13 & 144 & 2.34 \\
\hline 2004-May 2007 & 1,092 & 15.05 & 287 & 3.95 & 111 & 1.53 & 496 & 6.84 & 165 & 2.27 \\
\hline Jun 2007-Dec 2007 & 215 & 16.90 & 61 & 4.79 & 16 & 1.26 & 87 & 6.84 & 37 & 2.91 \\
\hline 2008 & 326 & 14.85 & 124 & 5.65 & 31 & 1.41 & 139 & 6.33 & 27 & 1.23 \\
\hline
\end{tabular}


Table 2

Numbers of cases and incidence rates per 100,000 person-years of traffic deaths, by preventive policies, for motorcyclists. Cali, Colombia, 1998-2008.

\begin{tabular}{|c|c|c|c|c|}
\hline \multirow[b]{3}{*}{ Policies for Motorcycles } & \multicolumn{4}{|c|}{ Traffic Injury Deaths in Motorcyclists } \\
\hline & \multicolumn{2}{|c|}{ Overall Mortality } & \multicolumn{2}{|c|}{ Motorcyclists } \\
\hline & Cases & Rate & Cases & Rate \\
\hline \multicolumn{5}{|l|}{ Traffic Regulation } \\
\hline No intervention & 1,685 & 19.33 & 439 & 5.04 \\
\hline Prohibition of transit 6 p.m. & 59 & 16.04 & 17 & 4.62 \\
\hline Prohibition of transit 10 p.m. & 108 & 16.12 & 34 & 5.07 \\
\hline Prohibition of transit 11 p.m. & 819 & 17.24 & 197 & 4.15 \\
\hline Night traffic regulation & 776 & 15.29 & 226 & 4.45 \\
\hline Prohibition of transit 12 p.m. & 499 & 15.53 & 163 & 5.07 \\
\hline \multicolumn{5}{|l|}{ Use of Safety Elements } \\
\hline No intervention & 1,896 & 19.42 & 493 & 5.05 \\
\hline Helmet use law & 629 & 17.10 & 153 & 4.16 \\
\hline Helmet use + reflective jacket & 1,421 & 15.19 & 430 & 4.60 \\
\hline \multicolumn{5}{|l|}{ Prohibition of passengers } \\
\hline No intervention & 1,899 & 19.36 & 498 & 5.08 \\
\hline Prohibition of passengers & 2,047 & 15.76 & 578 & 4.45 \\
\hline
\end{tabular}

Table 3

Number of cases and incidence rates per 100,000 person-years of traffic deaths, by alcohol restriction policies. Cali, Colombia, 1998-2008.

\begin{tabular}{|c|c|c|c|c|c|c|c|c|c|c|}
\hline & \multicolumn{10}{|c|}{ Traffic Injury Deaths } \\
\hline & \multicolumn{2}{|c|}{ Overall Mortality } & \multicolumn{2}{|c|}{ Motorcyclists } & \multicolumn{2}{|c|}{ Vehicle } & \multicolumn{2}{|c|}{$\underline{\text { Pedestrians }}$} & \multicolumn{2}{|c|}{ Cyclists } \\
\hline & Cases & Rate & Cases & Rate & Cases & Rate & Cases & Rate & Cases & Rate \\
\hline \multicolumn{11}{|l|}{ Alcohol restriction policies } \\
\hline Lax Policy 4 a.m. & 314 & 20.37 & 93 & 6.03 & 43 & 2.79 & 138 & 8.95 & 32 & 2.08 \\
\hline Moderately Restrictive 3 a.m. & 1,637 & 16.25 & 443 & 4.40 & 185 & 1.84 & 745 & 7.40 & 230 & 2.28 \\
\hline Restrictive Policy 2 a.m. & 1,639 & 18.25 & 463 & 5.16 & 221 & 2.46 & 742 & 8.26 & 192 & 2.14 \\
\hline Most Restrictive Policy 1 a.m. & 262 & 15.89 & 58 & 3.52 & 39 & 2.36 & 122 & 7.40 & 40 & 2.43 \\
\hline Full Restrictive Policy 6 p.m. & 94 & 17.05 & 19 & 3.45 & 11 & 2.00 & 47 & 8.53 & 14 & 2.54 \\
\hline
\end{tabular}

Table 4

Multivariate analysis. IRRs of traffic injury deaths associated with alcohol restriction policies. Cali, Colombia, 1998-2008

\begin{tabular}{|c|c|c|c|c|}
\hline \multirow[b]{2}{*}{ Variables } & \multicolumn{2}{|c|}{ Unadjusted analysis } & \multicolumn{2}{|c|}{ Multiple Regression Analysis } \\
\hline & IRR (95\%CI) & $P$ Value & IRR (95\%CI) & $P$ Value \\
\hline \multicolumn{5}{|c|}{ Alcohol restriction policies comparisons } \\
\hline \multicolumn{5}{|l|}{ Overall traffic injury mortality } \\
\hline Lax Policy 4 a.m. & 1.00 & & 1.00 & \\
\hline Moderately Restrictive 3 a.m. & $0.81(0.71-0.92)$ & 0.001 & $0.84(0.72-0.97)$ & $0.019 * *$ \\
\hline Restrictive Policy 2 a.m. & $0.90(0.79-1.02)$ & 0.087 & $0.88(0.76-1.02)$ & 0.097 \\
\hline Most Restrictive Policy 1 a.m. & $0.76(0.64-0.90)$ & 0.001 & $0.70(0.58-0.85)$ & $<0.001 * * *$ \\
\hline Full Restrictive Policy 6 p.m. & $0.84(0.66-1.06)$ & 0.158 & $0.86(0.65-1.15)$ & 0.316 \\
\hline \multicolumn{5}{|l|}{ Motorcycles } \\
\hline Lax Policy 4 a.m. & 1.00 & & 1.00 & \\
\hline Moderately Restrictive 3 a.m. & $0.74(0.59-0.93)$ & 0.011 & $0.78(0.59-1.04)$ & 0.089 \\
\hline Restrictive Policy 2 a.m. & $0.85(0.68-1.08)$ & 0.188 & $0.78(0.58-1.03)$ & 0.079 \\
\hline Most Restrictive Policy 1 a.m. & $0.57(0.40-0.80)$ & 0.001 & $0.55(0.38-0.81)$ & $0.002 * * *$ \\
\hline Full Restrictive Policy 6 p.m. & $0.57(0.35-0.95)$ & 0.033 & $0.52(0.29-0.94)$ & $0.032 * *$ \\
\hline \multicolumn{5}{|l|}{ Vehicles } \\
\hline Lax Policy 4 a.m. & 1.00 & & 1.00 & \\
\hline Moderately Restrictive 3 a.m. & $0.67(0.47-094)$ & 0.021 & $0.79(0.54-1.15)$ & 0.222 \\
\hline
\end{tabular}




\begin{tabular}{|c|c|c|c|c|}
\hline \multirow[b]{2}{*}{ Variables } & \multicolumn{2}{|c|}{ Unadjusted analysis } & \multicolumn{2}{|c|}{ Multiple Regression Analysis } \\
\hline & IRR (95\%CI) & $P$ Value & IRR (95\%CI) & $P$ Value \\
\hline Restrictive Policy 2 a.m. & $0.88(0.63-1.24)$ & 0.473 & $0.82(0.57-1.19)$ & 0.296 \\
\hline Most Restrictive Policy 1 a.m. & $0.82(0.53-1.29)$ & 0.403 & $0.65(0.41-1.04)$ & 0.075 \\
\hline Full Restrictive Policy 6 p.m. & $0.72(0.36-1.42)$ & 0.808 & $0.78(0.39-1.56)$ & 0.479 \\
\hline \multicolumn{5}{|l|}{ Pedestrians } \\
\hline Lax Policy 4 a.m. & 1.00 & & 1.00 & \\
\hline Moderately Restrictive 3 a.m. & $0.84(0.70-1.00)$ & 0.061 & $0.85(0.69-1.05)$ & 0.130 \\
\hline Restrictive Policy 2 a.m. & $0.92(0.77-1.11)$ & 0.402 & $0.91(0.74-1.11)$ & 0.978 \\
\hline Most Restrictive Policy 1 a.m. & $0.80(0.63-1.03)$ & 0.085 & $0.71(0.54-0.93)$ & $0.012^{* *}$ \\
\hline Full Restrictive Policy 6 p.m. & $0.96(0.68-1.34)$ & 0.808 & $0.93(0.65-1.31)$ & 0.674 \\
\hline \multicolumn{5}{|l|}{ Cyclists } \\
\hline Lax Policy 4 a.m. & 1.00 & & 1.00 & \\
\hline Moderately Restrictive 3 a.m. & $1.11(0.76-1.63)$ & 0.525 & $1.20(0.79-1.83)$ & 0.381 \\
\hline Restrictive Policy 2a.m. & $1.03(0.70-1.51)$ & 0.875 & $1.12(0.74-1.70)$ & 0.583 \\
\hline Most Restrictive Policy 1a.m. & $1.14(0.71-1.83)$ & 0.593 & $1.23(0.74-2.06)$ & 0.424 \\
\hline Full Restrictive Policy 6p.m. & $1.23(0.65-2.34)$ & 0.525 & $1.37(0.71-2.67)$ & 0.351 \\
\hline
\end{tabular}

The final regression models accounted for age, sex, weekends, holidays, motorcycle-specific policies, political city administrations, national traffic policy, fractional polynomials and sine-cosine pairs.

Table 5

Sensitivity analysis. IRRs of traffic injury deaths associated with alcohol restriction policies. Cali, Colombia, 2001-2008

\begin{tabular}{|c|c|c|c|c|}
\hline \multirow{2}{*}{ Variables } & \multicolumn{2}{|c|}{ Unadjusted analysis } & \multicolumn{2}{|c|}{ Multiple regression analysis } \\
\hline & IRR (95\%CI) & $P$ Value & IRR (95\%CI) & $P$ Value \\
\hline \multicolumn{5}{|c|}{ Alcohol restriction policies comparisons } \\
\hline \multicolumn{5}{|l|}{ Overall traffic injury mortality } \\
\hline Lax Policy 4 a.m. & 1.00 & & 1.00 & \\
\hline Moderately Restrictive 3 a.m. & $0.87(0.75-1.01)$ & 0.083 & $0.83(0.70-0.99)$ & $0.035^{* *}$ \\
\hline Restrictive Policy 2 a.m. & $0.89(0.76-1.04)$ & 0.159 & $0.95(0.78-1.14)$ & 0.327 \\
\hline Most Restrictive Policy 1 a.m. & $0.77(0.60-0.97)$ & 0.030 & $0.73(0.55-0.97)$ & $0.028 * *$ \\
\hline Full Restrictive Policy 6 p.m. & $0.81(0.60-1.11)$ & 0.195 & $0.87(0.59-1.30)$ & 0.499 \\
\hline \multicolumn{5}{|l|}{ Motorcycles } \\
\hline Lax Policy 4 a.m. & 1.00 & & 1.00 & \\
\hline Moderately Restrictive 3 a.m. & $0.77(0.58-1.02)$ & 0.069 & $0.66(0.48-0.91)$ & $0.012 * *$ \\
\hline Restrictive Policy 2 a.m. & $0.82(0.61-1.10)$ & 0.188 & $0.79(0.56-1.12)$ & 0.193 \\
\hline Most Restrictive Policy 1 a.m. & $0.52(0.31-0.86)$ & 0.011 & $0.46(0.26-0.83)$ & $0.009 * * *$ \\
\hline Full Restrictive Policy 6 p.m. & $0.55(0.28-1.07)$ & 0.079 & $0.38(0.16-0.90)$ & $<0.001 * * *$ \\
\hline \multicolumn{5}{|l|}{ Vehicles } \\
\hline Lax Policy 4 a.m. & 1.00 & & 1.00 & \\
\hline Moderately Restrictive 3 a.m. & $0.83(0.53-1.30)$ & 0.418 & $0.82(0.50-1.35)$ & 0.434 \\
\hline Restrictive Policy 2 a.m. & $0.85(0.53-1.34)$ & 0.481 & $0.86(0.51-1.45)$ & 0.572 \\
\hline Most Restrictive Policy 1 a.m. & $0.84(0.42-1.66)$ & 0.619 & $0.52(0.23-1.13)$ & 0.100 \\
\hline Full Restrictive Policy 6 p.m. & $0.72(0.36-1.42)$ & 0.808 & $1.06(0.42-2.67)$ & 0.899 \\
\hline \multicolumn{5}{|l|}{ Pedestrians } \\
\hline Lax Policy 4 a.m. & 1.00 & & 1.00 & \\
\hline Moderately Restrictive 3 a.m. & $0.93(0.74-1.17)$ & 0.531 & $0.92(0.71-1.19)$ & 0.528 \\
\hline Restrictive Policy 2 a.m. & $0.98(0.77-1.24)$ & 0.846 & $0.95(0.73-1.23)$ & 0.679 \\
\hline Most Restrictive Policy 1 a.m. & $0.81(0.57-1.16)$ & 0.253 & $0.82(0.54-1.24)$ & 0.340 \\
\hline Full Restrictive Policy 6 p.m. & $0.84(0.53-1.34)$ & 0.475 & $0.82(0.51-1.33)$ & 0.424 \\
\hline \multicolumn{5}{|l|}{ Cyclists } \\
\hline Lax Policy 4 a.m. & 1.00 & & 1.00 & \\
\hline Moderately Restrictive 3 a.m. & $1.12(0.72-1.75)$ & 0.606 & $1.34(0.81-2.22)$ & 0.250 \\
\hline Restrictive Policy 2 a.m. & $0.99(0.63-1.58)$ & 0.999 & $1.13(0.67-1.89)$ & 0.647 \\
\hline Most Restrictive Policy 1 a.m. & $1.32(0.72-2.42)$ & 0.376 & $1.52(0.75-3.08)$ & 0.244 \\
\hline Full Restrictive Policy 6 p.m. & $1.33(0.62-2.87)$ & 0.462 & $1.71(0.76-3.85)$ & 0.196 \\
\hline
\end{tabular}

The final regression models accounted for age, sex, weekends, holidays, motorcycle-specific policies, political city administrations, national traffic policy, fractional polynomials and sine-cosine pairs 


\section{Discussion}

We found that the local implementation of more restrictive alcohol policies in the city of Cali was associated with a decreased risk of road traffic deaths. We found that this association was significant when controlling for several confounders and sustained in the subgroups of motorcyclists and pedestrians. This suggests, consistent with prior literature, that alcohol control policies can reduce societal harm and potential associated costs (Anderson, Chisholm, \& Fuhr, 2009).

Specifically, we found that when a policy was enacted to restrict alcohol availability after 1 a.m., the risk of traffic deaths was reduced by $30 \%$. We also found that when the most restrictive policy was in effect, the risk of motorcyclist's deaths was reduced by $45 \%$. This finding suggests that when the purchase of alcohol is limited, driving behavior changes: people drive less, drive more safely, and/or are less likely to drive while impaired by alcohol.

The differences in findings between modes of transport can be explained by several factors. The significant effect of the most restrictive and full restrictive policies in the mortality of motorcyclists may be explained by the enforcement measures implemented while these interventions were in effect. The increased number of checkpoints and the control mechanisms used by the traffic police (e.g., taking a vehicle off the road if the driver was intoxicated) are good examples of this.

When the most restrictive policy was in effect, we found a non-significant decrease in the risk of fatal vehicular crashes. This finding suggests that control mechanisms failed, likely because of the lack of resources (e.g., breathalyzers) or inadequate numbers of traffic control personnel in the streets.

Interestingly, mortality in pedestrians decreased during the most restrictive policy. This suggests that restricting alcohol consumption in public may reduce the number of people walking in the street while impaired by alcohol. Alcohol restriction enforcement policies included fining and arresting individuals who were consuming alcohol in public places, so it is likely that many pedestrians under the influence of alcohol were identified, and that this helped to prevent the risk of injury.

It is likely that the interventions did not have an effect on cyclists because of many factors and variables that we were unable to considered in the analysis (e.g., the construction of specific roads for bicycles). Alcohol control policies may be not an effective intervention to decrease their mortality.

There are several factors that may explain the inconsistent results across the different policies. In the case of the full restrictive policy, the lack of significance may be due to the relatively small number of days when this intervention was in effect and, therefore, the limited number of crashes during that time. This policy was usually applied only for one or two days.

We found a non-significant reduction of road traffic mortality when restrictive policies were in effect. This finding suggests that either the owners of bars did not comply with the policy adequately, or citizens perceived the early closing as repressive and thus did not comply with the law consistently.

The significant result of the moderately restrictive policy may be explained by how the intervention was applied. Although we do not know the specific dates on which this occurred, it is known that several times, bar owners worked together with the police to identify drivers of vehicles and motorcyclists who were under the influence of alcohol. This situation is reflected in the overall mortality and sensitivity analysis.

The significant result of the most restrictive policy may be explained by the fact that the the city was on a critical security alert during those periods of time, so alcohol restrictions were reinforced with other interventions (e.g., motorcycles policies). It is likely that these policies interacted to decrease the risk of mortality.

The validity of the results for the most restrictive policy may be criticized on the grounds that it was only implemented twice in separate years, unlike the restrictive and moderate policies, which were in effect for long periods of time. However, this study was a time series analysis and the unit of analysis was the day of occurrence of road traffic deaths; therefore, the number of nonconsecutive days of the most restrictive policy was sufficient to demonstrate its effect.

Almost all implementations of the lax policies took place around December, during the holidays. It may be observed that their effect is seasonal, because the data experiences regular and predictable changes that recur every calendar year. This may be a limitation, because we estimated the effect of the other interventions at different times of the year.

We addressed these factors using an interrupted time series analysis adjusted for known political variables, time trends and seasonality. The current study provides an analysis with reliable data about constantly changing hours of alcohol restriction and addresses the effect of these interventions over time on road traffic mortality.

Another limitation is that we were unable to establish the degree to which alcohol control policies were the cause of the variations in road traffic deaths at the individual level, or how many of these deaths were directly due to alcohol. Our methods provide an incomplete picture of the relationship between the availability of alcohol and the act of driving under its influence, because there is no information about drinking patterns in the population, such as frequency, quantity, variability of drinking and factors of drinking locations (Bouffard, Bergeron, \& Bouffard, 2007; 
Felson, 1987; Gruenewald et al., 1996; Gruenewald \& Ponicki, 1995).

Restriction policies decrease the availability of alcohol in the population by banning its sale and consumption after certain hours (Anderson et al., 2009; Giesbrecht, 2000; Gruenewald \& Ponicki, 1995; Voas, Tippetts, \& Fell, 2003). Enforcing these interventions by increasing both perceived and actual arrests and penalty risk reduces the number of traffic injuries related to alcohol consumption (Chamberlain \& Solomon, 2002; Eger, 2006). However, it is difficult to establish whether vendors and consumers were compliant with the policy and how well the city enforced it. In addition, the perception of the legislation by the owners of bars and discotheques and the people of Cali remains unknown. Nonetheless, the aim of the interventions was to reduce alcohol sales and consumption, and this ecological study takes a public health approach to evaluate the effect of alcohol restriction policies on changes in road traffic death rates in the population (Holder, 2002; Perez et al., 2007; Sanchez et al., 2011; Villaveces et al., 2000; Vingilis et al., 2005).

\section{Conclusion}

Our findings suggest that more restrictive alcohol control policies reduced traffic-related mortality in the city of Cali, Colombia. Specifically, reducing the hours of alcohol sales and public consumption was associated with a decrease in motorcyclist injury death rates. Future work should examine how alcohol restriction policies influence alcohol consumption and alcohol-risk-related behavior.

\section{Acknowledgments}

We are indebted to the staff of the Institute for Peace Promotion and Violence/Injury Prevention (CISALVA), Universidad del Valle, Cali, Colombia, who worked on the management and cleaning process of the data. We would like to thank the operative committee of the Cali Crime Observatory's fatal injury surveillance system, composed of diverse local entities. We would like to thank Luis Echeverry, a fourth-year medical student (Universidad del Valle, Colombia), who collected most of the alcohol control policy information.

\section{References}

Anderson, P., Chisholm, D., \& Fuhr, D. C. (2009). Alcohol and Global Health 2: Effectiveness and costeffectiveness of policies and programmes to reduce the harm caused by alcohol. Lancet, 373(9682), 2234 2246.

Babor, T. F., Caetano, R., Casswell, S., Edwards, G., Giesbrecht, N., Graham, K., . . . Rossow, I. (2010). Alcohol: No ordinary commodity-a summary of the second edition. Addiction, 105, 769-779. doi:10.1111/J.1360-0443.2010.02945.X
Bouffard, L. A., Bergeron, L. E., \& Bouffard, J. A. (2007). Investigating the impact of extended bar closing times on police stops for DUI. Journal of Criminal Justice, 35, 537-545. doi:10.1016/J.Jcrimjus.2007.07.006

Chamberlain, E., \& Solomon, R. (2002). The case for a $0.05 \%$ criminal law blood alcohol concentration limit for driving. Injury Prevention, 8, iii1-iii17.

Concha-Eastman, A., Espitia, V. E., Espinosa, R., \& Guerrero, R. (2002). [Epidemiology of homicides in Cali, Colombia, 1993-1998: Six years of a populationbased model]. Revista panamericana de salud publica [Pan American journal of public health], 12, 230-239.

Cook, T., \& Campbell, D. (1979). Quasi-experimentation, design and analysis issues for field settings. Boston, MA, United States: Houghton Mifflin Company.

National Administrative Department of Statistics. DANE. (2010). Proyecciones de poblacion [Population projections] [Internet]. Retrieved from http://www.dane.gov.co/index.php?option=com_conte nt\&view $=$ article\&id $=75 \&$ Itemid $=72$

Eger, R. J. (2006). Policy instruments in injury crashesTraffic law enforcement and alcohol prohibition. Highway safety: Law enforcement; alcohol; Driver training; Safety planning and management; Commercial vehicles; and motorcycles. (1969), 45-49.

Espitia-Hardeman, V., Velez, L., Munoz, E., GutierrezMartinez, M. I., Espinosa-Vallin, R., \& ConchaEastman, A. (2008). [Impact of interventions directed toward motorcyclist death prevention in Cali, Colombia: 1993-2001]. Salud Publica Mex, 50 Suppl 1, S69-77. doi:S0036-36342008000700011 [pii]

Felson, M. (1987). Routine activities and crime prevention in the developing metropolis. Criminology, 25, 911932. doi:10.1111/j.1745-9125.1987.tb00825.x

Giesbrecht, N. (2000). Roles of commercial interests in alcohol policies: Recent developments in North America. Addiction, 95, S581-595.

Gruenewald, P. J., Millar, A. B., Treno, A. J., Yang, Z., Ponicki, W. R., \& Roeper, P. (1996). The geography of availability and driving after drinking. Addiction, 91, 967-983.

Gruenewald, P. J., \& Ponicki, W. R. (1995). The relationship of the retail availability of alcohol and alcohol sales to alcohol-related traffic crashes. Accident Analysis and Prevention, 27, 249-259.

Guerrero, R., \& Concha-Eastman, A. (2001). An epidemiological approach for the prevention of urban violence: The case of Cali, Colombia. World Health Population, 4(11).

Gutierrez-Martinez, M. I., Del Vallin, R. E., Fandino, A., \& Oliver, R. L. (2007). The evaluation of a surveillance system for violent and non-intentional injury mortality in Colombian cities. International Journal of Injury Control and Safety Promotion, 14, 77-84. doi:10.1080/17457300701234425

Hahn, R. A., Kuzara, J. L., Elder, R., Brewer, R., Chattopadhyay, S., Fielding, J., . . . Lawrence, B. (2010). Effectiveness of policies restricting hours of alcohol sales in preventing excessive alcohol consumption and related harms. [Review]. American Journal of Preventive Medicine, 39, 590-604. doi:10.1016/j.amepre.2010.09.016 
Holder, H. D. (2002). Prevention of alcohol and drug "abuse" problems at the community level: What research tells us. Substance Use \& Misuse, 37, 901921. doi: 10.1081/Ja-12000458

Institute for Peace Promotion and Violence/Injury Prevention (CISALVA). (2008). Informativo del Observatorio de Muertes por Lesiones de Causa Externa en el Área Metropolitana de Cali [Internet]. Retrieved from http://vigilesiones.univalle.edu.co/ informes/boletines/boletin11.pdf.

Kedem B., \& Fokianos, K. (2002). Regression Models for time series analysis. New York, NY, United States: Wiley-Interscience.

Landerman, L. R., Land, K. C., \& Pieper, C. F. (1997). An empirical evaluation of the predictive mean matching method for imputing missing values. Sociological Methods \& Research, 26, 3-33.

Middleton, J. C., Hahn, R. A., Kuzara, J. L., Elder, R., Brewer, R., Chattopadhyay, S., . . . Lawrence, B. (2010). Effectiveness of policies maintaining or restricting days of alcohol sales on excessive alcohol consumption and related harms. [Review]. American Journal of Preventive Medicine, 39, 575-589. doi:10.1016/j.amepre.2010.09.015

Perez, K., Marl-Dell'Olmo, M., Tobias, A., \& Borrell, C. (2007). Reducing road traffic injuries: Effectiveness of speed cameras in an urban setting. American Journal of Public Health, 97, 1632-1637. doi:10.2105/Ajph.2006.093195

Royston, P., \& Altman, D. G. (1994). Regression using fractional polynomials of continuous covariatesParsimonious Parametric Modeling. Applied Statistics-Journal of the Royal Statistical Society Series C, 43, 429-467.

Sanchez, A. I., Villaveces, A., Krafty, R. T., Park, T., Weiss, H. B., Fabio, A., . . Gutierrez, M. I. (2011). Policies for alcohol restriction and their association with interpersonal violence: A time-series analysis of homicides in Cali, Colombia. International journal of epidemiology, 40, 1037-1046. doi:10.1093/ije/dyr051

United States Department of Transportation. (2009). Traffic safety facts 2009. A compilation of motor vehicle crash data from the fatality analysis reporting system and the general estimates system. Retrieved from http://www-nrd.nhtsa.dot.gov/Pubs/811402EE.pdf

Villaveces, A., Cummings, P., Espitia, V. E., Koepsell, T. D., McKnight, B., \& Kellermann, A. L. (2000). Effect of a ban on carrying firearms on homicide rates in two Colombian cities. JAMA, 283, 1205-1209. doi: 10.1001/jama.283.9.1205

Vingilis, E., McLeod, A. I., Seeley, J., Mann, R. E., Beirness, D., \& Compton, C. P. (2005). Road safety impact of extended drinking hours in Ontario. Accident Analysis \& Prevention, 37, 549-556. doi:10.1016/j.aap.2004.05.006

Vittinghoff, E., Glidden, D., Shiboski, S. C., \& McCulloch C. E. (2005). Regression methods in biostatistics. New York, NY, United States: Springer Science+Business Media, Inc.

Voas, R. B., Tippetts, A. S., \& Fell, J. C. (2003). Assessing the effectiveness of minimum legal drinking age and zero tolerance laws in the United States. Accident Analysis \& Prevention, 35, 579-587.

World Health Organization. (2010). Road traffic death rate by $W H O$ region and income level. Retrieved Oct. 26, 2013, from http://gamapserver.who.int/gho/interactive_charts/road safety/road_traffic_deaths2/atlas.html

World Health Organization. (2011). Global status report on alcohol and health 2011. Retrieved from http://www.who.int/substance_abuse/publications/glob al_alcohol_report/msbgsruprofiles.pdf 